\title{
O fotoperíodo e a giberelina estimulam o crescimento de Sterculia striata após a dormência vegetativa ${ }^{1}$
}

\author{
Jonathas Pereira das Graças², Jales Teixeira Chaves Filho ${ }^{3}$
}

\begin{abstract}
Resumo: Sterculia striata St. Hill \& Naudin (Malvales - Malvaceae) ocorre no Cerrado brasileiro apresentando queda foliar e dormência vegetativa na estação de redução do fotoperíodo e disponibilidade hídrica. Investigou-se a possibilidade desses fatores abióticos influenciam a retomada do crescimento em Sterculia striata após a dormência. Para isso, o fotoperíodo foi aumentado $(3 \mathrm{~h}$ ) e plantas receberam ou não irrigação. $\mathrm{O}$ aumento do fotoperíodo foi decisivo para as plantas iniciarem a retomada do crescimento e expandirem a área foliar, pois, o mesmo ocorreu em condições de restrição hídrica total atingindo $221,7 \mathrm{~cm}^{2}$ de área foliar aos 90 dias. Além disso, estimulou a um maior crescimento, pois aos 90 dias de experimento o fotoperíodo aumentado e irrigação a área foliar foi de $1.969,2 \mathrm{~cm}^{2}$ enquanto no fotoperíodo natural e adição de água obteve-se $1.377,8 \mathrm{~cm}^{2}$. No tratamento com fotoperíodo natural sem água foi de $7,2 \mathrm{~cm}^{2}$ por planta. A água foi crucial para a expansão foliar, entretanto, independente da adição de água o fotoperíodo aumentado proporcionou a retomada do crescimento, o que significa que a espécie usa o fotoperíodo como sinal para o crescimento. Durante a retomada do crescimento plantas de S. striata o alongamento caulinar foi influenciado pelo hormônio giberelina. Tendo em vista a utilização da espécie para fins paisagísticos e de reflorestamento, mudas de S. striata podem ser expostas a manipulação do fotoperíodo e aplicação hormonal, a fim de se manipular o crescimento e produzir mudas vigorosas.
\end{abstract}

Palavras-chave: Área foliar; chichá-do-cerrado; crescimento; expansão celular; fotoperíodo.

\section{The photoperiod and the gibberellin stimulates the growth of Sterculia striata after the dormancy}

\begin{abstract}
Sterculia striata St. Hill \& Naudin (Malvales - Malvaceae) occurs in the Brazilian Cerrado and displays foliar fall and vegetative dormancy in the season of decrease in photoperiod and water availability. Here, it was investigated the possibility for these abiotic factors influence the resumption of growth in this specie. For this purpose, the photoperiod was increased $(3 \mathrm{~h})$ and plants were irrigation or not. The increase of the photoperiod was critical for the plants to initiate the resumption of growth and to expand the leaf area, because the same occurred under conditions of total water restriction reaching $221.7 \mathrm{~cm}^{2}$ of leaf area at 90 days. In addition, it stimulated a greater growth because at the 90 days of experiment, in the increased photoperiod and irrigation the leaf area was of $1.969,2 \mathrm{~cm}^{2}$ while with natural photoperiod and addition of water this value was $1,377.8 \mathrm{~cm}^{2}$. In the treatment with natural photoperiod without water the leaf area was $7.2 \mathrm{~cm}^{2}$ per plant. Thus, the water was crucial for leaf expansion, however, regardless water supplement, the increased photoperiod provided growth resumption. This means that the species uses photoperiod as a signal for growth after its natural dormancy. During the growth resumption of plant $S$. striata the stem length was influenced by the hormone gibberellin. In order to use this specie for landscaping and reforestation purposes, $S$. striata seedlings may be exposed to photoperiod manipulation and hormonal application in order to manipulate growth and produce vigorous seedlings.
\end{abstract}

Keywords: Cell expansion; chichá-do-cerrado; growth; leaf area; photoperiod.

\footnotetext{
${ }^{1}$ Submetido em 11/10/2018 e a provado em 13/01/2019

${ }^{2}$ Dr. em Ciências: Fisiologia e Bioquímica de Plantas; Pontifícia Universidade Católica de Goiás (PUC), Escola de Ciências Agrárias e Biológicas, Goiânia-Goiás, CEP: 74605-010; E-mail: jonathaspg@ @live.com

${ }^{3}$ Dr. em Ciências: Fisiologia e Bioquímica de Plantas; Professor Adjunto, Pontifícia Universidade Católica de Goiás (PUC), Escola de Ciências Agrárias e Biológicas, Goiânia-Goiás, CEP: 74605-010; E-mail: jales.bio@ pucgoias.edu.br
}

Revista Agropecuária Técnica, Areia-PB, v. 39, n. 3, p. 228-237, 2018

DOI: 10.25066/agrotec.v39i3.42128 


\section{Introdução}

Os eventos fenológicos de abscisão e brotamento foliar ocorrem durante o ano todo em plantas nativas do Cerrado brasileiro. Entretanto, a abscisão é mais acentuada na estação seca e o brotamento ocorre pouco antes do início ou durante o período chuvoso (Rizzini, 1997). Já é de conhecimento universal que fatores característicos de cada espécie dão ritmo ao crescimento, influenciado externamente por condições ambientais como duração do fotoperíodo, temperatura, suprimento de nutrientes, disponibilidade hídrica e de carbono (Atkinson e Urwin, 2012; Krahmer et al., 2018).

Nesse contexto, dentre as diversas espécies do Cerrado, destaca-se Sterculia striata St. Hill \& Naudin (Malvales - Malvaceae) que apresenta em sua fenologia a abscisão foliar no início da estação seca no mês de julho seguido de dormência vegetativa e brotamento de setembro a outubro (Almeida et al., 1998). A espécie Sterculia striata é de grande beleza ornamental sendo conhecida popularmente como chichá-docerrado, pau-rei ou sapucaia e trata-se de uma planta decídua, heliófita, que pode ser encontrada em floresta semidecídua, assim como em transição para o cerradão, tanto em formações primárias como secundárias (Lorenzi, 2002). Sobre a espécie, têm se estudado, por exemplo, a composição de substratos para melhor crescimento de mudas (Silva et al., 2015), visto que $S$. striata possui potencial para reflorestamento de áreas degradadas, um problema crescente no Cerrado. Contudo, outros aspectos da fisiologia básica da planta ainda necessitam ser compreendidos.

Desde algum tempo a dormência envolvendo a parada no crescimento, formação de gemas terminais, queda foliar - tem sido mais estudada em plantas de clima temperado, devido sua influência na sobrevivência das espécies em invernos rigorosos (Din et al., 2015) e maior número de estudos científicos em países desenvolvidos. Embora no cerrado os fatores ambientais sejam distintos de ambientes temperados, é possível que a dormência seja associada a uma vantagem adaptativa, como resistência à seca, e deve ser levada em consideração para o manejo racional de plantas nativas.
Nossa primeira hipótese é de que a retomada do crescimento em $S$. striata, após a dormência vegetativa, crítico, por exemplo, para o manejo racional de mudas, possa não estar ligada apenas à disponibilidade hídrica, marcadamente reduzida no cerrado, mas também a outros fatores do ambiente como redução no fotoperíodo entre junho e setembro. $\mathrm{O}$ fotoperíodo pode ser entendido como um complexo aspecto de interação entre os vegetais e o ambiente, sendo que a percepção do comprimento do dia habilita os organismos para uma adaptação às trocas de estações, prevenindo os efeitos adversos e conferindo-lhes vantagens seletivas (Thomas e Vince-Prue, 1997). Em plantas, a percepção do fotoperíodo exerce influência em aspectos como a tuberização, senescência, brotação, dormência, floração, defesa contra a herbivoria e em eventos circadianos como degradação noturna de amido (Greenhan e McClung, 2015; Hannapel et al., 2017). Para o desencadeamento destas respostas percepção do estímulo luminoso deve ocorrer nos órgãos fotorreceptores como folhas, gemas, parte de flores, epiderme dos frutos e as sementes (Larcher, 2000; Krahmer et al., 2018). Assim, a diminuição da duração do dia, associado com a chegada do período de seca provavelmente exerce influência no crescimento das plantas no Cerrado.

Em plantas utilizadas como modelo para estudos de fisiologia, observa-se que a retomada no crescimento após um período de dormência vegetativa é bastante complexa envolvendo várias moléculas chave como os hormônios. Dentre eles, a classe hormonal das giberelinas é importante para o alongamento caulinar, expansão foliar via fotomorfogênese, formação de sementes, transição de fase vegetativa para reprodutiva, etc (Hauvermale et al., 2012). O mecanismo de ação das giberelinas envolve degradação de proteínas que normalmente reprimem as vias de resposta e posteriormente ativação transcricional de genes (Schwechheimer, 2008). A transdução de sinais em resposta ao hormônio ainda é matéria de debate, mas já foi observado que enzimas e espécies reativas de oxigênio podem sinalizar ou influenciar diretamente a parede das células para promover crescimento sob influência das giberelinas (Achard et al., 2008). Um desafio ao se estudar as giberelinas é a presença de várias

Revista Agropecuária Técnica, Areia-PB, v. 39, n. 3, p. 228-237, 2018

DOI: 10.25066/agrotec.v39i3.42128 
isoformas endógenas: $\mathrm{GA}_{1}, \mathrm{GA}_{3}, \mathrm{GA}_{4}, \mathrm{GA}_{7}$. Uma estratégia de abordar é aplicando-se o inibidor de biossíntese paclobutrazol (Olszewski et al., 2002).

Por se tratar de uma planta ornamental e decídua, investigaram-se os fatores possivelmente relacionados à queda foliar, parada e retomada no crescimento de Sterculia striata, ocasionado pela estação seca. A hipótese é que não é apenas a restrição hídrica que condiciona a dormência vegetativa, mas sinais do ambiente como fotoperíodo também estão relacionados a mesma. Investigou-se também a participação de reguladores endógenos como a classe hormonal das giberelinas na retomada do crescimento após a dormência vegetativa. Ou seja, objetivou-se com este trabalho avaliar a restrição hídrica, fotoperíodo e giberelinas na superação da dormência de Sterculia striata.

\section{Material e Métodos}

Nesse trabalho, em um primeiro experimento foi investigada a influência da disponibilidade hídrica e do fotoperíodo sobre a retomada do crescimento das plantas de Sterculia striata durante 90 dias. Em um segundo experimento foi investigada a ação do hormônio giberelina sobre o crescimento de plantas após os 90 dias de restrição hídrica iniciais.

Os experimentos iniciaram no mês de julho até dezembro de 2009. As plantas foram mantidas em condições de estufa no Laboratório de Biologia Vegetal do Departamento de Biologia pertencente à Pontifícia Universidade Católica de Goiás.

\subsection{Obtenção de mudas e condições de desenvolvimento}

Os experimentos foram conduzidos em estufa de crescimento vegetal. As plantas foram obtidas através da germinação de sementes e no início do experimento datavam um ano e meio de idade. As mesmas foram mantidas em sacos plásticos de 20 x $30 \mathrm{~cm}$ com substrato composto por Latossolo Vermelho e areia na proporção de $3: 1$, respectivamente.

A temperatura e umidade relativa do ar foram monitoradas durante o período experimental utilizando-se um termohigrômetro. A temperatura média foi de $29{ }^{\circ} \mathrm{C}$. A média das máximas de temperatura foi de $36,3 \pm 3,3{ }^{\circ} \mathrm{C}$ e das mínimas foi de $25,3 \pm 2,1{ }^{\circ} \mathrm{C}$. A média de umidade relativa foi de $63 \%$. A média das máximas de umidade relativa foi de $86,5 \pm 6,1 \%$ e das mínimas de 51,5 $\pm 5,8 \%$.

Nas condições de estufa utilizadas os experimentos não dispunham de sulfite para filtrar a radiação solar em diferentes comprimentos de onda. A média de radiação dentro da estufa foi de aproximadamente 450 $\mu \mathrm{mol}$ fótons $\mathrm{m}^{2} \mathrm{~s}^{-1} \mathrm{em}$ plena luminosidade às 13 horas do dia.

\subsection{Aplicação de regimes hídricos e de fotoperíodo nas plantas}

Antes do início dos experimentos, todas as plantas permaneceram 33 dias sem irrigação, simulando a condição ocorrente em ambiente natural neste mesmo período. Durante este período de restrição hídrica ocorreu a queda total das folhas em todas as plantas que já havia se iniciado naturalmente, mesmo quando eram regadas. Quando a queda foliar se completou, visualmente as plantas permaneceram em dormência vegetativa.

Com o objetivo de comparar o efeito da disponibilidade hídrica e fotoperíodo sobre o crescimento de Sterculia striata foi montado um experimento com quatro tratamentos. Os tratamentos consistiram de plantas situadas em fotoperíodo natural com água $\left(\mathrm{FTn}+\mathrm{H}_{2} \mathrm{O}\right)$, fotoperíodo natural sem adição de água (FTn$\mathrm{H}_{2} \mathrm{O}$ ), fotoperíodo aumentado com água $\left(+\mathrm{FT}+\mathrm{H}_{2} \mathrm{O}\right)$; fotoperíodo aumentado sem água $\left(+\mathrm{FT}-\mathrm{H}_{2} \mathrm{O}\right)$. Cada tratamento foi composto por 8 repetições. Cada planta em um saco plástico foi considerada uma repetição.

Para a determinação do número de horas de luz diária (fotoperíodo natural) foram utilizados os valores fornecidos por Esalq/USP (2009), sendo que o mês de julho apresentou 11,2 horas de luz de acordo com a latitude do município de Goiânia-Goiás, evidenciando menor fotofase, em relação aos outros meses do período experimental (Tabela 1). Nos tratamentos com fotoperíodo aumentado foram acrescidas 3 horas no fotoperíodo diário, sendo uma hora pela manhã entre as 05:00 e 06:00 horas e duas horas após o crepúsculo das 18:00 às 20:00 horas (Tabela 1). Para o acréscimo de luz foi utilizada uma lâmpada do tipo fluorescente luz do dia, com emissão de aproxidamente 45 $\mu$ mol.fótons. $\mathrm{m}^{2} . \mathrm{s}^{-1}$. No tratamento com aumento 
de fotoperíodo, entre as 20:00 e as 06: 00 foi colocado uma lona de polietileno preto acoplada a uma placa de poliestireno branco impedindo assim que a luz propagasse lateralmente dentro da estufa de crescimento para outras plantas. Além disso havia uma distância de aproximadamente cinco metros entre os tratamentos com ou sem fotoperíodo aumentado.

Tabela 1. Representação dos tratamentos com as condições de fotoperíodo natural (horas de luz) e com aumento de 3 horas do fotoperíodo e de C e D para a latitude $16^{\circ}$ segundo Esalq/USP

\begin{tabular}{ccccc}
\hline Tratamentos * & \multicolumn{3}{c}{ Fotoperíodo (h) } & Outubro \\
\cline { 2 - 5 } & Julho & Agosto & Setembro & 12,4 \\
$\mathrm{FTn}+\mathrm{H}_{2} \mathrm{O}$ & 11,2 & 11,6 & 12 & 12,4 \\
$\mathrm{FTn}-\mathrm{H}_{2} \mathrm{O}$ & 11,2 & 11,6 & 12 & 15,4 \\
$+\mathrm{FT}+\mathrm{H}_{2} \mathrm{O}$ & 14,2 & 14,6 & 15 & 15,4 \\
$+\mathrm{FT}-\mathrm{H}_{2} \mathrm{O}$ & 14,2 & 14,6 & 15 & \\
\hline
\end{tabular}

* $\mathrm{FTn}+\mathrm{H} 2 \mathrm{O}=$ fotoperíodo natural com água, $\mathrm{FTn}-\mathrm{H} 2 \mathrm{O}=$ fotoperíodo natural com água, $+\mathrm{FT}+\mathrm{H} 2 \mathrm{O}=$ fotoperíodo aumentado sem água, +FT-H2O = fotoperíodo aumentado sem água.

Nos tratamentos com adição de água foram fornecidos $500 \mathrm{~mL}$ de água a cada dois dias, a fim de umedecer o solo. Após o surgimento da primeira folha, a cada 20 dias foram fornecidos nutrientes através da solução de Hoagland e Arnon, preparada segundo a metodologia descrita por Maestri et al. (2000). Nos tratamentos sem adição de água as plantas permaneceram em restrição hídrica total durante todo o experimento. A adição de água e aumento do fotoperíodo ocorreram no mesmo dia, marcando o início dos experimentos.

\subsection{Tratamento das plantas com reguladores de crescimento}

Para o tratamento das plantas com reguladores de crescimento giberelina $e$ paclobutrazol foram utilizadas plantas que permaneceram por 90 dias de restrição hídrica total, simulando as condições no ambiente natural. Após este período de modo aleatório as plantas foram divididas em quatro tratamentos: plantas que receberam somente água, plantas que receberam solução de giberelina, plantas que receberam solução de paclobutrazol e plantas sem água. Cada tratamento foi composto por quatro repetições, sendo a repetição uma planta.

No tratamento com aplicação de solução de giberelina foram fornecidos $200 \mathrm{~mL}$ numa concentração de $100 \mathrm{ppm}$ de giberelina $\left(\mathrm{GA}_{3}\right)$ ativa por planta através do produto comercial Pro-Gibb $^{\circledR}$. No tratamento com solução de paclobutrazol foram adicionados $200 \mathrm{~mL}$ com $0,128 \mathrm{mg} \cdot \mathrm{ml}^{-1}$ do produto ativo por planta, através do produto comercial Cultar ${ }^{\circledR}$. Logo após o solo foi mantido próximo a capacidade de campo até o término experimental. $\mathrm{O}$ mesmo ocorreu no tratamento com adição de somente água. No tratamento sem adição de água as plantas permaneceram sob restrição hídrica total durante todo período.

\subsection{Análise de crescimento}

A análise de crescimento das plantas para a determinação da retomada da atividade metabólica nas plantas dos tratamentos foi realizada através da quantificação não destrutiva da área foliar e do número de folhas a cada sete dias, segundo a metodologia descrita por Benincasa (2003). Para determinação da área, as folhas, considerando-se os tecidos após o final do pecíolo, tiveram a área circulada em papel sulfite e o contorno da área foliar foi recortado no papel. A seguir a área da folha recortada teve a massa aferida. Essa massa da área da folha recortada foi comparada ao peso de uma área de papel conhecida, e, assim, foi calculado a área foliar.

Aos 90 dias de experimento foram efetuadas medidas de crescimento do caule em todos os tratamentos. As médias dos parâmetros examinados no dia final de experimento foram analisadas através do teste de Duncan ao nível de 5\% de significância.

\section{Resultados e Discussão}

\subsection{Regime hídrico e fotoperíodo no crescimento de Sterculia striata}

A disponibilidade hídrica e o fotoperíodo influenciaram o crescimento de Sterculia striata após um período de dormência vegetativa, sendo 
a percepção do fotoperíodo crucial para retomada do crescimento após o período de abscisão foliar e dormência vegetativa.

A primeira evidência de que o aumento do fotoperíodo em 3 horas influenciou a retomada do crescimento em Sterculia striata foi observado nas plantas mantidas em total restrição hídrica, pois, aos 57 dias após a suspensão da rega, foi registrado brotamento da parte aérea (Figura 1).

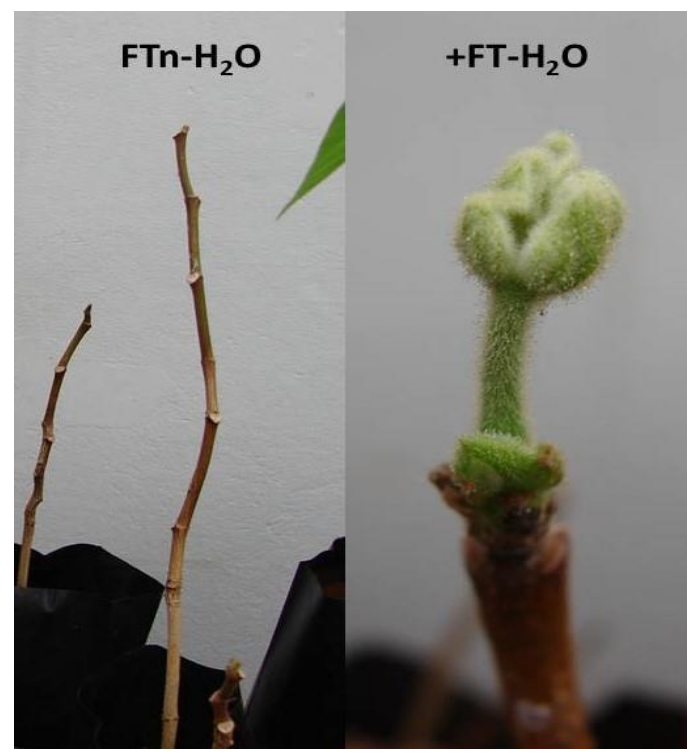

Figura 1 Ápice caulinar em Sterculia striata (Malvales - Malvaceae) aos 57 dias do no tratamento com fotoperíodo normal sem adição de água (FTn$\mathrm{H}_{2} \mathrm{O}$ ). No tratamento com fotoperíodo aumentado em 3 horas e sem adição de água $\left(+\mathrm{FT}-\mathrm{H}_{2} \mathrm{O}\right)$ é observado brotamento foliar.

Normalmente, nessa época as plantas teriam disponíveis 11,6 horas de luz, mas, em função do tratamento receberam 14,6 horas de luz diária. O brotamento provavelmente ocorreu às expensas da água e amido de reserva da raiz tuberosa de Sterculia striata (Mariano, 2009). Aos 90 dias de experimento as mesmas demonstraram uma média de área foliar de $221,7 \mathrm{~cm}^{2}$. Em plantas mantidas sob fotoperíodo natural e com restrição hídrica total durante 90 dias não houve incremento na área foliar, sendo a média de 7,2 $\mathrm{cm}^{2}$ por planta resultante de um brotamento sem expansão (Figura 2). Nas plantas com fotoperíodo natural e adição de água houve brotamento foliar, sendo observada aos 41 dias uma média da área foliar de $23,3 \mathrm{~cm}^{2}$ (Figura 2). Entretanto, em plantas que receberam água com aumento do fotoperíodo em 3 horas, já aos 34 dias após início da irrigação e aumento de fotoperíodo foi observado brotamento foliar, com área foliar média de $39,9 \mathrm{~cm}^{2}$. Também aos 90 dias, no tratamento com fotoperíodo aumentado e adição de água a área foliar foi de $1.969,2 \mathrm{~cm}^{2}$, enquanto que no tratamento com fotoperíodo natural e água a média foi de $1.377,8 \mathrm{~cm}^{2}$ (Figura 2).

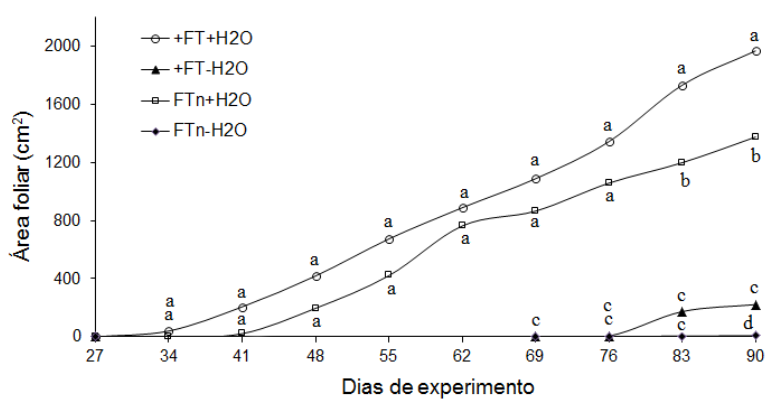

Figura 2 Área foliar $\left(\mathrm{cm}^{2}\right)$ por planta de Sterculia striata sob diferentes regimes de irrigação e fotoperíodo natural ou aumentado em 3 horas. $+\mathrm{FT}+\mathrm{H} 2 \mathrm{O}$ : Tratamento com fotoperíodo aumentado e adição de água. +FT-H2O: Tratamento com fotoperíodo aumentado sem adição de água. FTn+H2O: Tratamento com fotoperíodo natural com adição de água. FTn-H2O: Tratamento com fotoperíodo natural sem adição de água. Letras indicam diferença estatística entre os tratamentos no mesmo dia pelo teste de Duncan ao nível de $5 \%$ de significância.

Juntos, esses resultados evidenciam que a manutenção do solo em capacidade de campo contribuiu para expansão foliar. A pressão de turgescência nas células garantida pela disponibilidade hídrica é importante para que haja expansão celular, isto é, quando as paredes são forçadas a se distender aumentado as células em volume e causando crescimento (Tenhaken, 2015). Isso explica o crescimento praticamente insignificante nos tratamentos com restrição hídrica. Entretanto, o estímulo luminoso do fotoperíodo aumentado acelerou o metabolismo das plantas para a brotação de novas folhas, uma vez que o mesmo ocorreu independente do fornecimento de água para as plantas. A área foliar no tratamento com fotoperíodo aumentado e adição de água foi significativamente maior que no tratamento com fotoperíodo natural e adição de água. Tendo em vista que as condições na como a temperatura e umidade relativa na estufa de crescimento foram iguais, o fotoperíodo aumentado potencializou o aumento na área foliar da espécie. 
O número de folhas por plantas também foi influenciado pelos diferentes regimes de água e fotoperíodo. Aos 90 dias nas plantas do tratamento com aumento de fotoperíodo e água foi observada uma média de 4,4 folhas por planta e no tratamento com fotoperíodo natural e adição de água este valor foi de 2,8 folhas por planta (Tabela 2). Conforme o esperado, nos tratamentos de total restrição hídrica esse parâmetro foi menor, sendo que com fotoperíodo natural e aumentado as médias foram de $1,1 \mathrm{e}$ 1,3 folhas por planta, respectivamente.

Tabela 2 Média do número de folhas por planta de Sterculia striata aos 90 dias de experimento

\begin{tabular}{|c|c|c|c|c|}
\hline \multirow{2}{*}{ Dias de experimento } & \multicolumn{4}{|c|}{ Tratamentos* } \\
\hline & $+\mathrm{FT}+\mathrm{H}_{2} \mathrm{O}$ & $+\mathrm{FT}-\mathrm{H}_{2} \mathrm{O}$ & $\mathrm{FTn}+\mathrm{H}_{2} \mathrm{O}$ & $\mathrm{FTn}-\mathrm{H}_{2} \mathrm{O}$ \\
\hline 90 & $4,4 \mathrm{a}$ & $1,3 \mathrm{c}$ & $2,8 \mathrm{~b}$ & $1,1 \mathrm{c}$ \\
\hline
\end{tabular}

Em conjunto, a área foliar e o número de folhas por planta de Sterculia striata desenvolveram-se melhor em plantas que receberam água com fotoperíodo aumentado. $\mathrm{O}$ fotoperíodo aumentado se constituiu no estímulo para o brotamento e expansão das folhas (Figura 1). Essas folhas no início são drenos de carbono até sua formação e maturidade fisiológica, mas logo após, passam a exportar produtos da fotossíntese permitindo o crescimento vegetativo dos diferentes órgãos das plantas (Sulpice et al., 2014). Resultados semelhantes foram obtidos por Moreira et al. (1999) que estudando os efeitos do fotoperíodo no crescimento de Gomphrena macrocephala, espécie ocorrente no cerrado verificaram que os parâmetros comprimento de haste e o número de pares de folhas apresentaram maiores quando as plantas foram submetidas à fotoperíodos mais longos, entre 12 e 16 horas, em relação ao tratamento com 8 horas de luz.
A média do crescimento do caule aos 90 dias foi maior nos tratamentos que receberam água sendo $12,3 \mathrm{~cm}$ no tratamento com fotoperíodo aumentado seguido do tratamento com fotoperíodo natural com $11,4 \mathrm{~cm}$ por planta. Nos tratamentos sem água com fotoperíodo aumentado e natural os valores foram 2,4 e 1,1 $\mathrm{cm}$ de caule, respectivamente (Tabela 3 ). Assim como a expansão foliar, o crescimento do caule também foi influenciado pela disponibilidade hídrica. A redução do crescimento na parte aérea em função do regime hídrico tem sido relatada em plantas jovens de outras espécies arbóreas. Figueirôa et al. (2004) estudando o efeito de diferentes capacidades de campo no solo sobre o crescimento de Myracrodruon urundeuva verificaram que as plantas mantidas a $75 \%$ da capacidade de campo apresentaram aos 60 dias de experimento maior média de altura quando comparadas às plantas tratadas com 50 e $25 \%$ de capacidade de campo.

Tabela 3 Média do crescimento do caule $(\mathrm{cm})$ por planta de Sterculia striata aos 90 dias de experimento

\begin{tabular}{ccccc}
\hline \multirow{2}{*}{ Dias de experimento } & \multicolumn{4}{c}{ Tratamentos $^{*}$} \\
& $+\mathrm{FT}+\mathrm{H}_{2} \mathrm{O}$ & $+\mathrm{FT}-\mathrm{H}_{2} \mathrm{O}$ & $\mathrm{FTn}+\mathrm{H}_{2} \mathrm{O}$ & $\mathrm{FTn} \mathrm{H}_{2} \mathrm{O}$ \\
\cline { 2 - 5 } 90 & $12,3 \mathrm{a}$ & $2,4 \mathrm{~b}$ & $11,4 \mathrm{a}$ & $1,1 \mathrm{~b}$ \\
\hline
\end{tabular}

${ }^{*}\left(+\mathrm{FT}+\mathrm{H}_{2} \mathrm{O}\right)$, fotoperíodo aumentado sem água $\left(+\mathrm{FT}-\mathrm{H}_{2} \mathrm{O}\right)$; fotoperíodo natural com adição de água $\left(-\mathrm{FT}+\mathrm{H}_{2} \mathrm{O}\right)$ e fotoperíodo natural sem água $\left(-\mathrm{FT}-\mathrm{H}_{2} \mathrm{O}\right)$. Letras indicam diferença estatística entre os tratamentos pelo teste de Duncan ao nível de $5 \%$ de significância.

Através da análise da área foliar, do número de folhas por planta e do crescimento do caule de Sterculia striata constata-se que os fatores abióticos disponibilidade hídrica e fotoperíodo são importantes no desenvolvimento da espécie, pois favoreceram maior crescimento nas plantas.
A resposta das plantas frente aos fatores observados demonstra a adaptação às diferentes disponibilidades de recursos que podem ocorrer no habitat natural, o que é ecologicamente importante para a sobrevivência da espécie. 


\subsection{Hormônios exógenos no crescimento de Sterculia striata}

Após a aplicação do hormônio giberelina e do inibidor de sua síntese, paclobutrazol, as plantas foram mantidas diariamente em capacidade de campo. Um terceiro tratamento consistiu de fornecer apenas água para as plantas. Como controle em um tratamento as plantas foram mantidas em restrição hídrica total.
Quanto ao número de folhas por planta, a aplicação de água e giberelina apresentaram os maiores valores, obtendo-se aos 50 dias de experimento em média 4 folhas por planta para ambos (Tabela 4). Na aplicação de paclobutrazol e no tratamento sem água os valores foram de 2,5 e 1,8 folhas por planta, respectivamente, evidenciando a síntese de giberelina como crucial para produção de novas folhas pelas plantas (Tabela 4).

Tabela 4 Número médio de folhas por planta de Sterculia striata (Malvales - Malvaceae) nos tratamentos com adição de apenas água $\left(+\mathrm{H}_{2} \mathrm{O}\right)$, solução de giberelina e de paclobutrazol e no tratamento sem água $\left(-\mathrm{H}_{2} \mathrm{O}\right)$ em condições de estufa no período de outubro a novembro de 2009

\begin{tabular}{ccccc}
\hline \multirow{2}{*}{ Dias } & \multicolumn{3}{c}{ Tratamentos } \\
& $(+) \mathrm{H}_{2} \mathrm{O}$ & Giberelina & Paclobutrazol & $(-) \mathrm{H}_{2} \mathrm{O}$ \\
\cline { 2 - 5 } 15 & 3,0 & 2,0 & 2,5 & 1,8 \\
30 & 3,0 & 3,5 & 2,5 & 1,8 \\
50 & $4,0 \mathrm{a}^{*}$ & $4,0 \mathrm{ab}$ & $2,5 \mathrm{ab}$ & $1,8 \mathrm{~b}$ \\
\hline
\end{tabular}

*Letras indicam diferença estatística entre os tratamentos pelo teste de Duncan ao nível de 5\% de significância.

Quanto à área foliar, foi possível observar que al restrição hídrica inibiu o brotamento e crescimento das folhas (Tabela 5). $\mathrm{Na}$ deficiência de água no solo os processos de crescimento são inibidos nas plantas por afetar negativamente atividades como a síntese de proteínas, de parede celular assim como a expansão celular e manutenção da turgescência (Kudrev, 1994; Litvin et al., 2016).

Tabela 5. Área foliar $\left(\mathrm{cm}^{2}\right)$ por planta de Sterculia striata (Malvales - Malvaceae) nos tratamentos com adição de apenas água $\left(+\mathrm{H}_{2} \mathrm{O}\right)$, solução de giberelina e de paclobutrazol e no tratamento sem água $\left(-\mathrm{H}_{2} \mathrm{O}\right)$ em condições de estufa no período de outubro a novembro de 2009

\begin{tabular}{ccccc}
\hline \multirow{2}{*}{ Dias } & & \multicolumn{3}{c}{ Tratamentos } \\
& $(+) \mathrm{H}_{2} \mathrm{O}$ & Giberelina & Paclobutrazol & $(-) \mathrm{H}_{2} \mathrm{O}$ \\
\cline { 2 - 5 } 15 & $1.864,6$ & 911,7 & 843,2 & 0,0 \\
30 & $2.008,8$ & $1.349,3$ & $1.078,8$ & 0,0 \\
50 & $2.441,6 \mathrm{a}^{*}$ & $1.785,3 \mathrm{~b}$ & $1.078,8 \mathrm{~b}$ & $0,0 \mathrm{c}$ \\
\hline
\end{tabular}

*Letras indicam diferença estatística entre os tratamentos pelo teste de Duncan ao nível de 5\% de significância.

O tratamento onde as plantas receberam somente água obteve a maior média ao final do experimento aos 50 dias, sendo $2.441,6 \mathrm{~cm}^{2}$, seguido dos tratamentos com aplicação de giberelina e paclobutrazol onde foram observadas médias de $1.785,3$ e $1.078,8 \mathrm{~cm}^{2}$ de área foliar por planta, respectivamente (Tabela 5). No tratamento com paclobutrazol o maior valor deste parâmetro foi observado aos 30 dias após a aplicação com $1.078,8 \mathrm{~cm}^{2}$ permanecendo neste patamar até os 50 dias.

O paclobutrazol é um inibidor da biossíntese de giberelinas (Olszewski et al., 2002). Isto sugere que a biossíntese de giberelina é importante para garantir a contínua expansão das folhas após o período de dormência vegetativa. O controle do crescimento de órgãos não ocorre apenas em função da expansão celular, mas também depende da divisão celular. Todavia, em folhas de Festuca arundinacea (Poaceae) têm sido descrito o papel das giberelinas sobre a expansão celular para promoção do crescimento (Xu et al., 2016).

O crescimento do caule foi parâmetro de maior interesse para investigar o efeito da aplicação de $\mathrm{GA}_{3}$ e seu inibidor de síntese paclobutrazol, 
visto que um dos efeitos mais visíveis das giberelinas ocorre no alongamento caulinar (Olszewski et al., 2002). A aplicação de giberelina exerceu influência no alongamento do caule das plantas de Sterculia striata, pois em média foram $26,6 \mathrm{~cm}$, praticamente duas vezes maiores que no tratamento com apenas água, que obteve $14,5 \mathrm{~cm}$ de crescimento caulinar (Tabela $6)$.

Tabela 6 Média do crescimento do caule $(\mathrm{cm})$ por planta de Sterculia striata aos 30 e 50 dias de experimento nos tratamentos adição de apenas água $\left(+\mathrm{H}_{2} \mathrm{O}\right)$, solução de giberelina e de paclobutrazol e no tratamento sem água $\left(-\mathrm{H}_{2} \mathrm{O}\right)$ em condições de estufa no período de outubro a novembro de 2009

\begin{tabular}{ccccc}
\hline \multirow{2}{*}{ Dias } & \multicolumn{4}{c}{ Tratamentos } \\
& Giberelina & $(+) \mathrm{H}_{2} \mathrm{O}$ & Paclobutrazol & $(-) \mathrm{H}_{2} \mathrm{O}$ \\
\cline { 2 - 5 } 30 & 26,2 & 9,7 & 4,2 & 3,9 \\
50 & $26,2 \mathrm{a}^{*}$ & $14,5 \mathrm{~b}$ & $4,4 \mathrm{c}$ & $3,9 \mathrm{c}$ \\
\hline
\end{tabular}

*Letras indicam diferença estatística entre os tratamentos pelo teste de Duncan ao nível de 5\% de significância.

Nas plantas onde houve aplicação de paclobutrazol o crescimento caulinar foi de 4,4 $\mathrm{cm}$ (Tabela 6), aproximadamente seis vezes menor quando comparado à média das plantas tratadas com giberelina e somente água. Isto é uma evidência de que em Sterculia striata as giberelinas endógenas atuam no processo de crescimento caulinar após a dormência vegetativa, ocasionada pela redução da disponibilidade hídrica e redução do comprimento do dia, conforme mostrado nos resultados anteriores. No ambiente natural o rápido crescimento do caule é importante para que a planta seja competitiva, na exploração de recursos como luminosidade. Resultados semelhantes foram obtidos por Siqueira et al. (2008) que estudando a aplicação de $\mathrm{GA}_{3}$ e paclobutrazol em Citrus volkameriana, observaram aos 50 dias após a aplicação uma diminuição no comprimento caulinar em função do aumento das doses de paclobutrazol, assim como a diminuição da área foliar por planta quando estas eram tratadas somente com paclobutrazol, sem a aplicação de giberelina.

O mecanismo de ação das giberelinas nos órgãos das plantas é um tema atual com importantes avanços, especialmente devido ao impacto na agricultura e produtividade. Em folhas, $\mathrm{GA}_{3}$ estimula a expansão controlando genes de endotransglicosilases que modificam as propriedades da parede celular para permitir a distensão da parede e alongamento celular ( $\mathrm{Xu}$ et al., 2016). O estresse hídrico reduz o crescimento de caules, não apenas pela perda de turgescência necessária para a expansão celular, mas também por alterar o metabolismo de giberelinas (Litvin et al., 2016).

\section{Conclusões}

Os fatores abióticos disponibilidade hídrica e fotoperíodo estimulam o crescimento vegetativo em plantas de Sterculia striata após a dormência vegetativa;

A aplicação de giberelina e inibição de sua biossíntese demonstraram a participação do hormônio na retomada do crescimento após 90 dias de restrição hídrica;

A aplicação de giberelina e fotoperíodo aumentado podem também ser manipulados, a fim de acelerar o crescimento das mudas, para fins paisagísticos ou de reflorestamento.

\section{Referências}

Achard, P.; Renou, J.; Berthome, R.; Harberd, N. P.; Genschik, P. Plant DELLAs restrain growth and promote survival of adversity by reducing the levels of reactive oxygen species. Current Biology, v.18, n.9, p.656-660, 2008. https://doi.org/10.1016/j.cub.2008.04.034

Almeida, S. P.; Proença, C. E.; Sano, S. M.; Ribeiro, J. F. Cerrado: espécies vegetais úteis. Brasília: Embrapa-CPAP, 1998. 464p.

Atkinson, N. J., Urwin, P. E. The interaction of plant biotic and abiotic stresses: from genes to the field. Journal of Experimental Botany, v.63, n.10, p.3523-3543 2012. https://doi.org/10.1093/jxb/ers100

Benincasa, M. M. P. Análise do crescimento de plantas (noções básicas). Jaboticabal: Funep, 2003. 42p.

Din, G. Y., Cohen, M., Kamenetsky, R. Database for herbaceous peony cultivated in 
warm climate regions: effects of temperature on plant dormancy and growth. Journal of Horticulture, v.2, n.3, p.1-7, 2015. http://dx.doi.org/10.2139/ssrn.248168

ESALQ/USP. Valores do fotoperíodo. Disponível em http://www.esalq.usp.br/departamentos/leb/aulas/lce306/f otoperiodo.html . Acesso em 5 jun. 2009.

Figueirôa, J. M.; Barbosa, D. C. A.; Simabukuro, E. A. Crescimento de plantas jovens de Myracrodruon urundeuva Allemão (Anarcadiaceae) sob diferentes regimes hídricos. Acta Botânica Brasilica, v.18, n.3, p.573-580, 2004. http://dx.doi.org/10.1590/S0102$\underline{3062004000300015}$

Greenhan, K.; McClung, R. Integrating circadian dynamics with physiological processes in plants. Nature Reviews Genetics, v. 16, n. 10, p. 598-610, 2015. https://doi.org/10.1038/nrg3976

Hannapel, D. J.; Sharma, P.; Lin, T.; Banerjee, A. K. The multiple signals that control tuber formation. Plant Physiology, v.174, n.2, p.845-856, 2017. https://doi.org/10.1104/pp.17.00272

Hauvermale, A. L.; Ariizumi, T.; Steber, C. M. Gibberellin signaling: a theme and variations on DELLA repression. Plant Physiology, $\begin{array}{llll}\text { v.160, } & \text { n.1, } & \text { p.83-92, }\end{array}$ https://doi.org/10.1104/pp.112.200956

Krahmer, J.; Ganpudi, A.; Abbas, A.; Romanowski, A.; Halliday, K. J. Phytochrome, carbon sensing, metabolism, and plant growth plasticity. Plant Physiology, v.176, n.1, p.1039-1048,

https://doi.org/10.1104/pp.17.01437

Kudrev, T. G. Água: vida das plantas. São Paulo. Editora Ícone, 1994. 178p.

Larcher, W. Ecofisiologia Vegetal. São Carlos: Editora Rima, 2000. 531p.

Litvin, A. G.; van Iersel, M. W.; Malladi, A. Drought stress reduces stem elongation and alters gibberellin-related gene expression during vegetative growth of tomato. Journal of the American Society for Horticultural Science, v. 141 n. 6, p. 591-597. 2016. https://doi.org/10.21273/JASHS03913-16

Lorenzi, H. Árvores brasileiras: manual de identificação e cultura de plantas arbóreas nativas do Brasil. São Paulo: Editora Nova Odessa, 2002. 384p.
Maestri, M.; Alvim, P. T.; Silva, M. A. P.; Mosquim, P. R.; Puschmam, R.; Cano, M. A. O.; Barros, R. S. Fisiologia Vegetal: exercícios práticos. Viçosa: Universidade Federal de Viçosa, 2000. 91p.

Mariano, J. S. Caracterização morfoanatômica dos órgãos vegetativos de plantas jovens de Sterculia striata St. Hil. et Naudin (Malvales - Malvaceae). 2009. Monografia (curso de Biologia). Departamento de Biologia. Pontifícia Universidade Católica de Goiás, Goiânia, 2009.

Moreira, M. F.; Vieira, C. C. J.; Zaidan, L. B. P. Efeito do fotoperíodo no crescimento e no padrão de acúmulo de frutanos em plantas aclimatizadas de Gomphrena macrocephala St. -Hil. (Amaranthaceae). Revista Brasileira de Botânica, v.22, n.3, p.397-403, 1999. http://dx.doi.org/10.1590/S0100-84041999000300008

Olszewski, N.; Sun, T.; Gubler, F. Gibberellin signaling: biosynthesis, catabolism, and response pathways. The Plant Cell, v.14, n.1, p.61-80, 2002. https://doi.org/10.1105/tpc.010476

Rizzini, C. T. Tratado de fitogeografia do Brasil: aspectos ecológicos, sociológicos e florísticos. Rio de Janeiro: Âmbito Cultural Edições, 1997. 747p.

Schwechheimer, C. Understanding gibberellic acid signaling - are there yet? Current Opnion in Plant Biology, v.11, n.1, p,9-15. 2008. https://doi.org/10.1016/j.pbi.2007.10.011

Silva, K, B.; Pinto, M. S. C.; Melo, E. N.; Pereira, L, M, Dantas, L. T.; Bezerra, M, D.; Nelto Almeida de Sousa. Influência de diferentes substratos na emergência $e$ crescimento inicial de plântulas de Chichá-docerrado (Sterculia striata A. St. Hill. \& Naudin) Sterculiaceae. Revista Agropecuária Técnica, v.36, n.1, p.176-182, 2015. https://doi.org/10.25066/agrotec.v36i1.24023

Sulpice, R.; Flis, A.; Ivakov, A, A.; Apelt, F.; Krohn, N.; Encke, B.; Abel, C.; Feil, R.; Lunn, J, E.; Stitt, M. Arabidopsis coordinates the diurnal regulation of carbon allocation and growth across a wide range of photoperiods. Molecular Plant, v.7, n.1, p.137-155, 2014. https://doi.org $/ 10.1093 / \mathrm{mp} / \mathrm{sst} 127$

Thomas, B.; Vince-Prue, D. Photoperiodism in Plants. San Diego. Academic Press Limited, 1997. 428p. 
Tenhaken, R. Cell wall remodeling under abiotic stress. Frontiers in Plant Science, v.7, n.5, p.1-9, 2015. https://doi.org/10.3389/fpls.2014.00771

Xu, Q.; Krishnan, S.; Merewitz, E.; Xu, J.; Huang, B. Gibberellin-regulation and genetic variations in leaf elongation for tall fescue in association with differential gene expression controlling cell expansion. Scientific Reports, v.6, $\quad$ n.1, p.1-12, 2016. https://doi.org/10.1038/srep30258 